Check for updates

Cite this: RSC Adv., 2017, 7, 33132

\title{
Portable melt electrospinning apparatus without an extra electricity supply
}

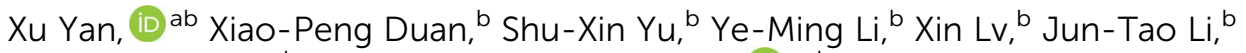 \\ Hong-Ying Chen, ${ }^{b}$ Xin Ning ${ }^{a}$ and Yun-Ze Long (D *ab
}

Melt electrospinning has attracted a lot of interest due to its advantages such as being solvent-free, lowcost and so on. However, previously reported melt electrospinning devices were usually complicated due to their necessary heating system. Moreover, the electrical heating system may cause electrostatic interference during the melt electrospinning process. For simplification, we designed a portable melt electrospinning setup based on an alcohol lamp (or a candle/lighter) as a heat source, which could make the setup work well without an extra power supply and electrostatic interference. Polymers such as polycaprolactone (PCL), poly(lactic acid) (PLA) and polyurethane (PU) were electrospun successfully into fibers with diameters of 13-60 $\mu \mathrm{m}$ using this apparatus. We also study the influence of various experimental parameters, such as the temperature of the charging barrel $\left(120-255^{\circ} \mathrm{C}\right.$, which can be adjusted by changing the heating distance), electrospinning distance $(6-14 \mathrm{~cm})$ and the inner diameter of the spinneret $(0.26-1.2 \mathrm{~mm})$, on the PCL fibers. This simple and safe device can be used as a demonstrator for the melt electrospinning process.

Received 2nd May 2017

Accepted 26th June 2017

DOI: $10.1039 / c 7 r a 04937 d$

rsc.li/rsc-advances interference between the heating system and electrospinning high voltage. However, the above mentioned heating devices were still relative complex and actually relying on electricity supply. This may limit the application of melt electrospinning especially in the case of outdoors or without power supply.

Moreover, to minimize the whole melt electrospinning device, the high-voltage power supply could be replaced by a Wimshurst generator ${ }^{12,13}$ or a portable high-voltage converter associated with batteries ${ }^{14}$ which enhanced the transportability and flexibility of these melt electrospinning apparatuses. While, the heating systems of these portable melt electrospinning devices were based on electrically-driven heating gun, which is used to heat the air through the electric heating wire. $^{13,14}$

For further simplification, we propose a portable melt electrospinning setup based on an alcohol lamp or a candle/lighter as heating system (which can generate a temperature of more than four hundred degrees celsius) and a hand generator associated with high-voltage converter as high voltage system in this article. The performance on melt electrospinning process of this device has been examined, which shows good practicality and portability than a conventional melt electrospinning setup especially in the case of without electric supply.

\section{Experimental}

\section{Portable melt electrospinning apparatus design}

Fig. 1 shows the schematic diagram and actual object of the portable melt electrospinning apparatus. The high voltage is 
(a)
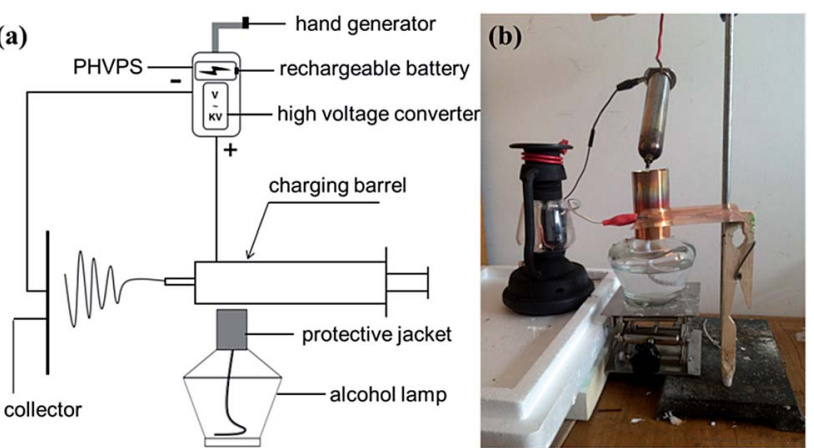

Fig. 1 (a) Schematic diagram of the portable melt electrospinning apparatus based on a portable hand generator as high-voltage power supply (PHVPS) and an alcohol lamp as heat source. (b) Actual picture of the prototype device in lab.

supplied by a home-made portable hand-generator-based highvoltage power supply (PHVPS) assembled by ourselves. The PHVPS includes a hand generator $(5 \mathrm{~V} / 200 \mathrm{~mA})$, a set of rechargeable batteries (12 V, NiMH AA) and a high voltage converter (F101, EMCO High Voltage Corporation), ${ }^{14,19}$ by which the electricity can be generated by the hand generator according. to electromagnetic induction and could be stored in the rechargeable batteries. Through the high voltage converter, a high voltage about $15 \mathrm{kV}$ can be obtained. The heating device is an alcohol lamp and the heating temperature of the charging barrel can be detected by a portable infrared thermometer (HT8863, HCJYET) and controlled by changing the heating distance. Metal needle is selected as spinneret with different inner diameter purchased from Longye Hardware Company. The collecting system was an aluminum foil.

\section{Materials and melt electrospinning process}

Polycaprolactone (PCL, average molecular weight of 80000 , purchased from SOLVAY), poly(lactic acid) (PLA, average molecular weight of 200000 , purchased from Nature Works) and polyurethane (PU, average molecular weight of 60000 , purchased from SOLVAY) were selected as the melt electrospinning materials. By using the designed handy electrospinning apparatus, the polymer granules were put into the charging barrel firstly and then adjust the distance between charging barrel and alcohol lamp to control the heating temperature to reach the melting point of these polymers, the melt electrospinning process can be achieved.

\section{Characterization}

The morphology of electrospun fibers can be examined by scanning electron microscope (SEM; Hitachi S4700, $20 \mathrm{kV}$ accelerating voltage). PCL fibers were also examined by the Fourier transform infrared spectroscopy (FTIR; Thermo Scientific Nicolet iN10). The pictures of the actual designed apparatus were recorded by a digital video camera (EX-ZR400, Canon).

\section{Results and discussion}

\section{Performance of the designed handy melt electrospinning device}

To examine the practicability of the designed melt electrospinning apparatus, we electrospun PCL, PLA and PU melt into fibers by using the designed device, and the SEM images of asspun fibers were shown in Fig. 2. During melt electrospinning, the temperature was controlled by adjusting the distance from the flame to the charging barrel and measured by a portable infrared thermometer. It is found that PCL, PLA and PU melt electrospun fibers can be fabricated successfully within a spinning distance of $10 \mathrm{~cm}$ under heating temperature of $150{ }^{\circ} \mathrm{C}$, $225{ }^{\circ} \mathrm{C}$ and $255^{\circ} \mathrm{C}$, respectively. The average diameters of asspun fiber are about $37.25 \mu \mathrm{m}$ (PCL), $32.19 \mu \mathrm{m}$ (PLA) and $40.35 \mu \mathrm{m}$ (PU). These results demonstrate the feasibility and stability of the simple device.

\section{Influence of the heating temperature}

Heating temperature plays a key role in melt electrospinning. ${ }^{6-8}$ For the designed handy melt electrospinning device, the heating system is an alcohol lamp, which can provide a temperature of more than $500{ }^{\circ} \mathrm{C}$. Moreover, the heating temperature can be adjusted by changing the distance from the flame to the charging barrel. To clarify the tunable heating temperatures of the designed device, we examined the influence of temperature on melt-spun fibers morphology. PCL was selected as the melt materials for its lower melting point about $59-64{ }^{\circ} \mathrm{C}$, and the SEM images of electrospun PCL fibers under different heating temperatures in the range of $120-180^{\circ} \mathrm{C}$ were shown in Fig. 3(ae). It is found that in all the temperature region of $120-180^{\circ} \mathrm{C}$, PCL melt can be electrospun into fibers, and the average diameter of as-spun fibers is obviously decreased from $43.05 \mu \mathrm{m}$ to $21.16 \mu \mathrm{m}$, as displayed in Fig. 3f. The reduced fiber diameter may due to the viscosity of polymer melt decreased with increasing temperature. ${ }^{7,20,21}$ Furthermore, it is found that when heating temperature was higher than $165{ }^{\circ} \mathrm{C}$, the fibers had begun to adhere to each other as shown in Fig. $3 \mathrm{~d}$ and e. Moreover, the color of the PCL melt turned to yellow after heating for ten minutes at $165^{\circ} \mathrm{C}$ and $180^{\circ} \mathrm{C}$, which may due to the decomposition of polymer. Therefore, heating temperatures of $150{ }^{\circ} \mathrm{C}$ were employed for PCL in the following experiments.

Fig. 4 shows the FTIR spectra of the melt electrospun PCL fibers fabricated by the designed apparatus under a heating temperature of $150{ }^{\circ} \mathrm{C}$, spinning distance of $10 \mathrm{~cm}$ and with spinneret of 22G. From the FTIR spectra, the chemical structure

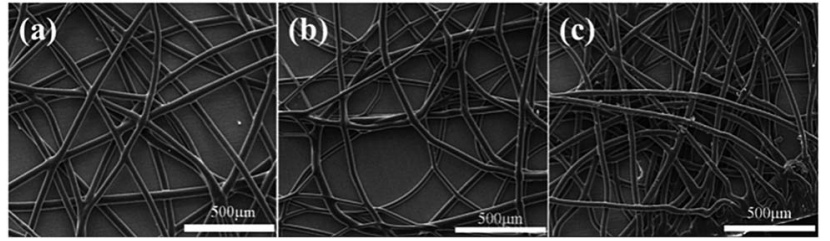

Fig. 2 SEM images of electrospun PCL (a), PLA (b) and PU (c) fibers with the designed handy melt electrospinning apparatus. 
of PCL can be obviously found, such as the characteristic peak at $2946 \mathrm{~cm}^{-1}$ and $2865 \mathrm{~cm}^{-1}$ corresponding to the asymmetric and symmetric $\mathrm{CH}_{2}$ stretching, the characteristic peak at 1720 $\mathrm{cm}^{-1}$ corresponding to the carbonyl stretching, and the characteristic peaks at $1293 \mathrm{~cm}^{-1}, 1240 \mathrm{~cm}^{-1}, 1190 \mathrm{~cm}^{-1}$ corresponding to $\mathrm{C}-\mathrm{C}$, asymmetric $\mathrm{C}-\mathrm{O}-\mathrm{C}$, OC-O stretching, respectively. ${ }^{13,22-24}$ The infrared spectroscopy obtained from the as-spun fibers indicated that the designed melt device can fabricated fibers without chemical property changing.

\section{Influence of electrospinning distance}

Besides the performance of the designed apparatus under different heating temperature, we also investigated the influence of spinning distance on as-spun fibers diameter by using the designed melt electrospinning device. In the melt electrospinning process, we selected PCL as the melt material and the heating temperature was set at $150{ }^{\circ} \mathrm{C}$. The SEM images of the melt electrospun PCL fibers prepared within different spinning distances in the range of $6-14 \mathrm{~cm}$ were shown in Fig. 5a-e. It is found that the average diameter of electrospun PCL fiber
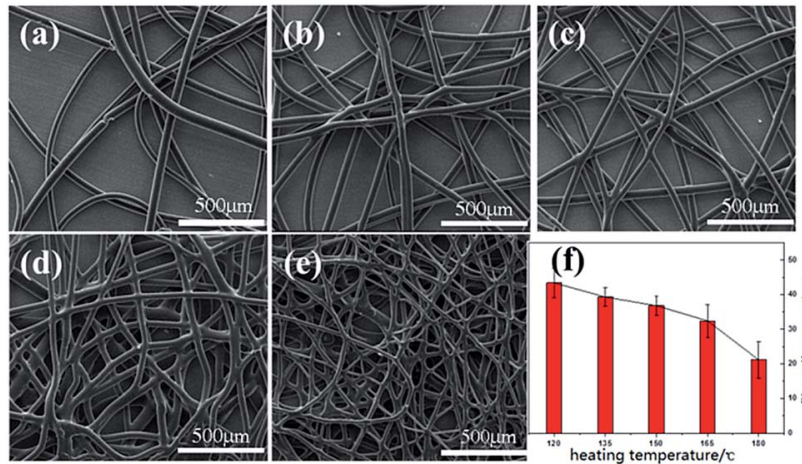

(f)

Fig. 3 SEM images of melt electrospun $\mathrm{PCL}$ fibers under heating temperatures of (a) $120^{\circ} \mathrm{C}$, (b) $135^{\circ} \mathrm{C}$, (c) $150^{\circ} \mathrm{C}$, (d) $165^{\circ} \mathrm{C}$, (e) $180^{\circ} \mathrm{C}$ within spinning distance of $10 \mathrm{~cm}$, and the relationship between average fiber diameter and heating temperature ( $f$ ).

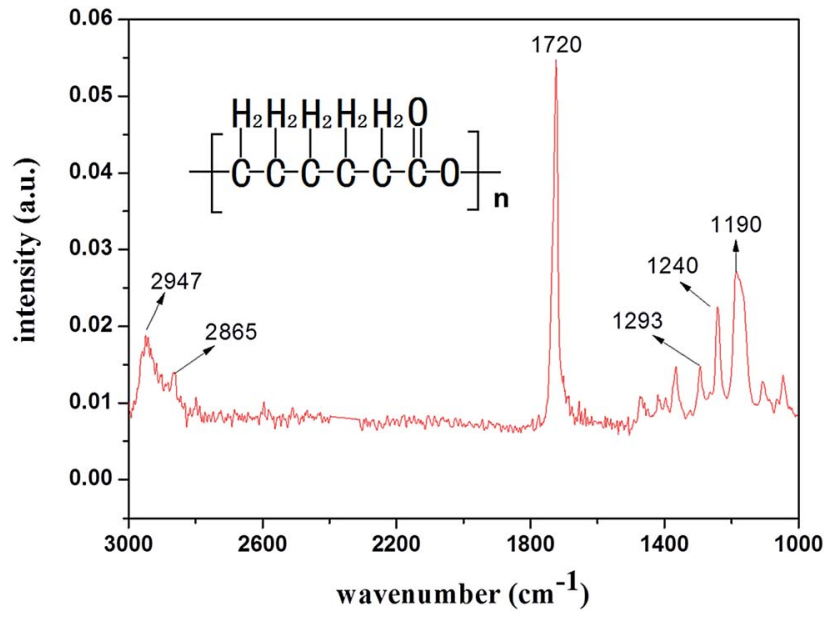

Fig. 4 FTIR spectra of the melt electrospun PCL fibers.

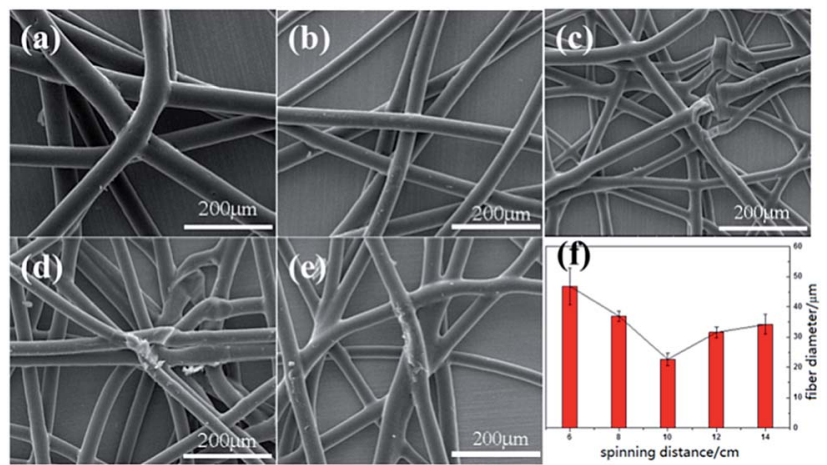

Fig. 5 SEM images of melt electrospun $P C L$ fibers under heating temperatures of $150{ }^{\circ} \mathrm{C}$ within different spinning distance of (a) $6 \mathrm{~cm}$, (b) $8 \mathrm{~cm}$, (c) $10 \mathrm{~cm}$, (d) $12 \mathrm{~cm}$, (e) $14 \mathrm{~cm}$, and (f) statistical histogram of the average fiber diameter via spinning distance.

reduced from $46.82 \mu \mathrm{m}$ to $22.63 \mu \mathrm{m}$ when the electrospinning distance increased from 6 to $10 \mathrm{~cm}$ as suggested in Fig. 5f, which can be attributed to a longer (lengthened) fiber tensile curing time for a longer spinning distance in the electric field. ${ }^{\mathbf{1 3 , 1 4 , 2 5}}$ However, the average diameter of as-spun PCL fiber increased from $22.63 \mu \mathrm{m}$ to $34.18 \mu \mathrm{m}$ when the spinning distance further increased to $14 \mathrm{~cm}$, since the electric field intensity became weaker with the increase of spinning distance. ${ }^{\mathbf{1 3 , 1 4 , 2 5}}$ It is suggested that the optimized spinning distance of the designed apparatus is about $10 \mathrm{~cm}$ in order to obtain fibers with smaller diameter. The relationship between the as-spun fiber diameter and spinning distance consists with the traditional melt e-spinning setup.

\section{The influence of spinneret inner diameter on fibers}

Fig. 6 showed the SEM images of melt electrospun PCL fibers fabricated with different inner diameter spinneret under a heating temperature of $150{ }^{\circ} \mathrm{C}$ and spinning distance of $10 \mathrm{~cm}$ by using the designed apparatus. The inner diameter of the metal spinneret is decreased from $1.2 \mathrm{~mm}$ to $0.26 \mathrm{~mm}$ with the increase of type label from $16 \mathrm{G}$ to $24 \mathrm{G}$. As can be found in

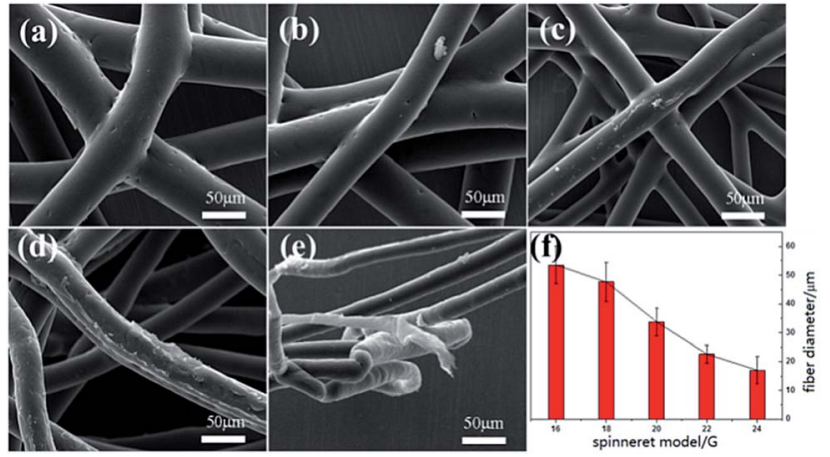

Fig. 6 SEM images of PCL melt electrospun fibers produced under a heating temperature of $150{ }^{\circ} \mathrm{C}$, a spinning distance of $10 \mathrm{~cm}$, a spinneret model of (a) $16 \mathrm{G}(1.2 \mathrm{~mm})$, (b) $18 \mathrm{G}(0.9 \mathrm{~mm})$, (c) $20 \mathrm{G}(0.62$ $\mathrm{mm}),(\mathrm{d}) 22 \mathrm{G}(0.41 \mathrm{~mm}),(\mathrm{e}) 24 \mathrm{G}(0.26 \mathrm{~mm})$, (f) statistical histogram of average fiber diameter. 


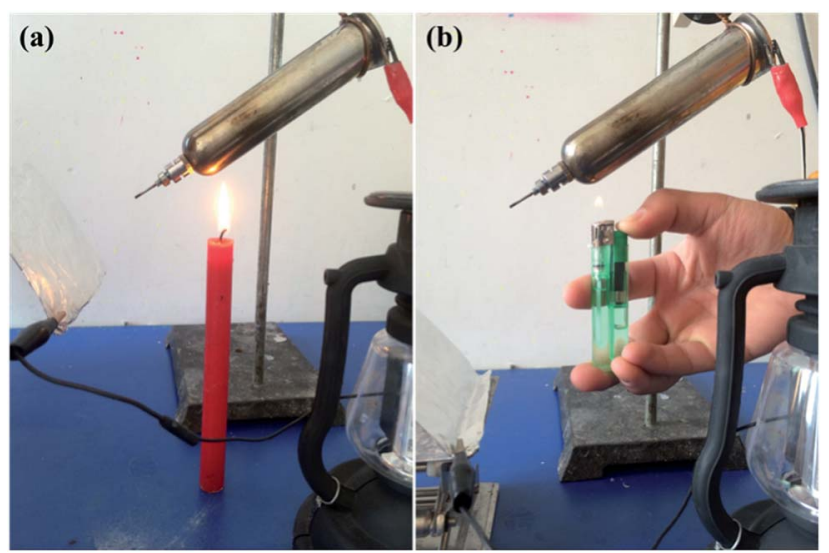

Fig. 7 The heating system of the designed apparatus can be changed into a candle (a) or a lighter (b).

Fig. 6a-e, the as-spun PCL fibers are relatively uniform and the diameter shows obviously decrease as the spinneret more fine. The relationship between the electrospun fibers diameter and spinneret diameter is shown in Fig. 6f, which is linear attenuation and agrees with the former study. ${ }^{26,27}$ Since the designed apparatus aims for simplicity, the syringe pump unit is deleted. The melt in charging barrel is flowed from the spinneret relying on gravitation, which may suggest that there would be some trouble for melt flow out from finer spinneret. Consequently, the optimum spinneret inner diameter is about $0.41 \mathrm{~mm}(22 \mathrm{G})$ is more suit for the designed apparatus.

\section{Other heating system for the designed apparatus}

As mentioned above, the heating system of the designed apparatus is an alcohol lamp, which was designed to reduce the possible electrostatic interference and can satisfy PCL, PLA and PU melts electrospinning. For further simplification, the heating system can be replaced by a candle or a lighter, as shown in Fig. 7. It is examined that a candle and lighter can provide a temperature of about $280{ }^{\circ} \mathrm{C}$ and $400{ }^{\circ} \mathrm{C}$, which can satisfy kinds of polymers melts electrospinning including but not limited to PCL, PLA and PU. ${ }^{6-8,28,29}$ Moreover, both of the candle and lighter heating systems show good convenience and easy to established. However, the burning candle is more stable than lighter. The replaceable heating system of the designed apparatus without electrostatic interference ensures the device may be easily constructed and suitable for outdoors applications and teaching demonstration.

\section{Conclusions}

In summary, a portable melt electrospinning apparatus based on an alcohol lamp and a portable hand-generator-based power supply has been proposed, which can work without extra electricity supply and avoid electrostatic interference in melt electrospinning process. The heating system of this device even can be replaced by a candle or lighter. The performance of this device for melt electrospinning was examined by electrospinning PCL, PLA and PU melt into fibers. Moreover, the electrospinning parameters of the designed apparatus such as heating temperature, electrospinning distance and spinneret diameter on electrospun fibers morphology were investigated. It is suggested that the designed apparatus is suitable for melt electrospinning in accordance with the common melt electrospinning device. Moreover, the designed device showed advantages for easily setting up and without extra power supply, which may guarantee the designed apparatus potential applications in teaching demonstration and outdoor applications.

\section{Acknowledgements}

This work was supported by the National Natural Science Foundation of China (51373082 and 51673103), and the Taishan Scholars Program of Shandong Province, China (ts20120528), the Shandong Provincial Key Research and Development Plan (2016GGX102011) and Shandong Provincial Natural Science Foundation, China (ZR2016EMB09).

\section{References}

1 R. H. Dong, C. C. Qin, X. Qiu, X. Yan, M. Yu, L. Cui, Y. Zhou, H. D. Zhang and Y. Z. Long, Nanoscale, 2015, 7, 19468; R. H. Dong, Y. X. Jia, C. C. Qin, L. Zhan, X. Yan, L. Cui, Y. Zhou, X. Y. Jiang and Y. Z. Long, Nanoscale, 2016, 8, 3482.

2 M. H. Liu, X. P. Duan, Y. M. Li, D. P. Yang and Y. Z. Long, Mater. Sci. Eng., C, 2017, 76, 1413-1423.

3 S. C. Zhang, H. Liu, F. L. Zuo, X. Yin, J. Y. Yu and B. Ding, Small, 2017, 13, 1603151.

4 G. F. Yu, X. Yan, M. Yu, M. Y. Jia, W. Pan, X. X. He, W. P. Han, Z. M. Zhang, L. M. Yu and Y. Z. Long, Nanoscale, 2016, 8, 2944.

5 Z. M. Huang, Y. Z. Zhang, M. Kotaki and S. Ramakrishna, Compos. Sci. Technol., 2003, 63, 2223.

6 T. D. Brown, P. D. Dalton and D. W. Hutmacher, Prog. Polym. Sci., 2016, 56, 116.

7 L. H. Zhang, X. P. Duan, X. Yan, M. Yu, X. Ning, Y. Zhao and Y. Z. Long, RSC Adv., 2016, 6, 53400.

8 W. M. Yang and H. Y. Li, IOP Conf. Ser.: Mater. Sci. Eng., 2014, 64, 012013.

9 R. J. Deng, Y. Liu, Y. Ding, P. C. Xie, L. Luo and W. M. Yang, J. Appl. Polym. Sci., 2009, 114, 166.

10 J. Lyons, C. Li and F. Ko, Polymer, 2004, 45, 7597.

11 P. D. Dalton, K. Klinkhammer, J. Salber, D. Klee and M. Möller, Biomacromolecules, 2006, 7, 686.

12 W. P. Han, Y. Y. Huang, M. Yu, J. C. Zhang, X. Yan, G. F. Yu, H. D. Zhang, S. Y. Yan and Y. Z. Long, Nanoscale, 2015, 7, 5603.

13 C. C. Qin, X. P. Duan, L. Wang, L. H. Zhang, M. Yu, R. H. Dong, X. Yan, H. W. He and Y. Z. Long, Nanoscale, 2015, 7, 16611.

14 X. Yan, M. Yu, L. H. Zhang, X. S. Jia, J. T. Li, X. P. Duan, C. C. Qin, R. H. Dong and Y. Z. Long, Nanoscale, 2016, 8, 209.

15 P. D. Dalton, J. Lleixa Calvet, A. Mourran, D. Klee and M. Möller, Biotechnol. J., 2006, 1, 998.

16 S. J. Kim, D. H. Jang, W. H. Park and B. M. Min, Polymer, 2010, 51, 1320. 
17 N. Ogata, S. Yamaguchi, N. Shimada, G. Lu, T. Iwata, K. Nakane and T. Ogihara, J. Appl. Polym. Sci., 2007, 104, 1640; N. Shimada, N. Ogata, H. Miyashita, K. Nakane and T. Ogihara, J. Textil Eng., 2008, 54, 143; S. Tian, N. Ogata, N. Shimada, K. Nakane, T. Ogihara and M. Yu, J. Appl. Polym. Sci., 2009, 113, 1282.

18 Y. Z. Long, Y. Y. Huang, R. H. Dong, X. Yan, W. P. Han, J. C. Zhang, X. P. Duan, C. C. Qin and D. P. Lin, China Pat., 201410409495.3, 2014.

19 P. A. Mouthuy, L. Groszkowski and H. Ye, Biotechnol. Lett., 2015, 37, 1107.

20 D. H. Reneker and I. Chun, Nanotechnology, 1996, 7, 216.

21 S. Sukigara, M. Gandhi, J. Ayutsede, M. Micklaus and F. Ko, Polymer, 2003, 44, 5721-5727.

22 H. J. Zhou, T. B. Green and Y. L. Joo, Polymer, 2006, 47, 7497.
23 L. G. Mobarakeh, M. P. Prabhakaran, M. Morshed, M. H. Nasr-Esfahani and S. Ramakrishna, Mater. Sci. Eng., C, 2010, 30, 1129.

24 L. Ghasemi-Mobarakeh, M. P. Prabhakaran, M. Morshed, M. H. Nasr-Esfahani and S. Ramakrishna, Biomaterials, 2008, 29, 4532.

25 X. Y. Li, H. C. Liu, J. N. Wang and C. J. Li, Polymer, 2012, 53, 248.

26 L. Larrondo and R. S. J. Manley, J. Polym. Sci., Polym. Phys. Ed., 1981, 19, 909.

27 S. A. Catledge, W. C. Clem, N. Shrikishen, S. Chowdhury, A. V. Stanishevsky, M. Koopman and Y. K. Vohra, Biomed. Mater., 2007, 2, 142.

28 Y. Kadomae, Y. Maruyama, M. Sugimoto, T. Taniguchi and K. Koyama, Fibers Polym., 2009, 10, 275-279.

29 H. Asai, M. Kikuchi, N. Shimada and K. Nakane, RSC Adv., 2017, 7, 17593. 